\title{
The Impact of Education and Training on the Level of Poverty or Social Exclusion in European Countries
}

\author{
Marcin Walczak \\ Lodz University of Technology, Poland \\ Stefana Żeromskiego Street, No 116, 90-924 Łódź \\ Faculty of Organization and Management \\ Piotrkowska Street, No 266, 90-361 Łódź \\ International Faculty of Engineering \\ Kpt. Franciszka Żwirki Street, No 36, 90-539 Łódź \\ Tel: +48-501-184-661Ｅ-mail: 244412@edu.p.lodz.pl
}

Received: January 29, 2022 Accepted: February 21, 2022 Published: February 28, 2022

doi:10.5296/ijld.v12i1.19520

URL: https://doi.org/10.5296/ijld.v12i1.19520

\begin{abstract}
Education is said to be the "great equalizer of the conditions of men". The aim of this paper is to examine the relationship between participation rate in education and training and people at risk of poverty and social exclusion. The source of data, used in the research, is Eurostat. The data represents the 25-64-year-old age group. The analyzed period is 2016-2020. It represents both genders in 34 European countries. Some countries were excluded from the analysis due to the lack of data for some years within the analyzed period. For each variable measures of descriptive statistics (measures of central tendency, measures of variability and measures of asymmetry) were calculated. Then the Pearson correlation of coefficient and coefficient of determination were computed. To assess the significance of the correlation of coefficient, hypothesis testing was performed. The procedure was performed using rejection region method and two-tailed p-vale method. Although, in 2016 and 2017, a strong linear correlation was detected between the participation rate in education and training and people at risk of poverty or social exclusion, its significance is gradually decreasing. Despite this, it should be emphasized that children born in poverty or in socially excluded families have a lower chance of succeeding in education and thus escape from the vicious circle of poverty. Thus, education should still be perceived as an important factor, and the main 'tool' to fight against poverty.
\end{abstract}

Keywords: Education, Europe, poverty, social exclusion, training 


\section{Introduction - Variables Description}

One can say that "training" is just another word for "education", but it is not. Education and training are terms which are absolutely related but do not mean the same. According to Merriam-Webster, America's most trusted online dictionary, education is defined as 'the knowledge, skill and understanding that you get from attending a school, college or university.'(2022) A similar definition of this term is provided by the Cambridge English Dictionary, which determines it as a process of 'teaching and learning in a school or college, or the knowledge that you get from this'.(2022) Training, on the other hand, is defined by these two sources as 'the skill, knowledge, or experience acquired by one who trains' and 'the process of learning the skills you need to do a particular job or activity'(2022), respectively. Based on these definitions, it can be concluded that education is a process of acquisition of broad knowledge and skills within an educational environment. Training refers to the acquisition of job-specific skills and knowledge required to perform given job. For the purpose of this study, data representing the 25-64-year-old age group were selected. The analyzed period is 2016-2020. The data is annual and measured in percentages. It represents both genders in 34 European countries. Some countries were excluded from the analysis due to the lack of data for some years within the analyzed period.

Table 1. Measures of central tendency applied to the participation rate in the education and training variable

\begin{tabular}{llllll}
\hline \multicolumn{5}{c}{ Measures of central tendency } \\
& $\begin{array}{l}\text { Arithmetic } \\
\text { in\%: }\end{array}$ & $\begin{array}{l}\text { mean } \\
\text { in \%ode }\end{array}$ & $\begin{array}{l}\text { Quartile 1 } \\
\text { in \%: }\end{array}$ & $\begin{array}{l}\text { Median } \\
\text { in \%: }\end{array}$ & $\begin{array}{l}\text { Quartile 3 } \\
\text { in \%: }\end{array}$ \\
\hline $\mathbf{2 0 1 6}$ & 7,13 & 18,8 & 5,275 & 8,05 & 16,525 \\
$\mathbf{2 0 1 7}$ & 7,11 & 2,3 & 4,825 & 8,75 & 17,2 \\
$\mathbf{2 0 1 8}$ & 6,98 & 8,5 & 5,775 & 8,5 & 18,45 \\
$\mathbf{2 0 1 9}$ & 7,35 & 8,2 & 5,025 & 8,2 & 19,25 \\
$\mathbf{2 0 2 0}$ & 6,21 & 11 & 4,25 & 7,55 & 15,475 \\
\hline
\end{tabular}

Source: Own elaboration based on data from Eurostat.

According to Table 1, it can be said that on average, the participation rate in education and training has a decreasing tendency, as the arithmetic mean felt from $7,13 \%$ in 2016 to $6,21 \%$ in 2020. The same tendency is observed in the calculated quartiles. In 2016, 25\% of all observations had values lower than or equal to $5,275 \%$, and $25 \%$ of all observations had values higher than $16,525 \%$. For the same variable, in $2020,25 \%$ of all observations have values lower than or equal to $4,35 \%$, and $25 \%$ of all observations have values higher than or 
equal to $15,475 \%$. The graph representing data can be found in Appendix as a Graph 1 .

The second variable, chosen for the analysis, was the rate of people at risk of poverty or social exclusion. The terms 'in risk of poverty' and 'social exclusion' were not defined by any reliable dictionary. Therefore, the definition provided by Eurostat, on its official website 'Statistics Explained', shall be treated as the most credible. According to this source, it "corresponds to the sum of people who are at risk of poverty, or severely materially and socially deprived or living in a household with a very low level of productivity"(2022). An individual is included only if it is in more than one of the situations mentioned above. The variable is expressed in percentages, which means that this is a share of the total population of a given country, which is at risk of poverty or social exclusion. For the purpose of this study, data representing all age groups was selected. The analyzed period is 2016-2020. The frequency of data is annual. It represents both genders in 34 European countries. Some countries were excluded from the analysis due to the lack of data for some years within the analyzed period.

Table 2. Measures of central tendency applied to people at risk of poverty or social exclusion variable

\begin{tabular}{llllll}
\hline \multicolumn{5}{c}{ Measures of central tendency } & \\
\hline & $\begin{array}{l}\text { Arithmetic mean } \\
\text { in\%: }\end{array}$ & $\begin{array}{l}\text { Mode } \\
\text { in \%: }\end{array}$ & $\begin{array}{l}\text { Quartile 1 } \\
\text { in \%: }\end{array}$ & $\begin{array}{l}\text { Median } \\
\text { in \%: }\end{array}$ & Quartile 3 in \%: \\
\hline $\mathbf{2 0 1 6}$ & 25,2 & 24,4 & 18,125 & 21,9 & 29,625 \\
$\mathbf{2 0 1 7}$ & 24,3 & 17 & 17,325 & 20,6 & 28,725 \\
$\mathbf{2 0 1 8}$ & 23,2 & 17,4 & 17,4 & 20 & 28,05 \\
$\mathbf{2 0 1 9}$ & 21,1 & 20,6 & 17,025 & 20,1 & 26,125 \\
$\mathbf{2 0 2 0}$ & 20,8 & 19,4 & 17,35 & 19,4 & 25,85 \\
\hline
\end{tabular}

Source: Own elaboration based on data from Eurostat.

On average, the rate of people at risk of poverty or social exclusion variable has a decreasing tendency, as the arithmetic mean was equal to $25,2 \%$ in 2016 and $20,8 \%$ in 2020 . The same tendency can be observed on the basis of the quartiles. In 2016, 25\% of all observations have values equal to or lower than $18,125 \%$, and $25 \%$ of observations have values equal to or greater than $29,625 \%$. In $2020,25 \%$ of all observations have values equal to or lower than $17,35 \%$ and $25 \%$ of all observations have values equal to or higher than $25,85 \%$. The graph representing data can be found in Appendix as a graph 2.

The study was limited by availability of data in Eurostat database. Some of European countries had to be excluded from the research due to the lack of data. This relates to second 
limitation - sample size that is 34 countries. The study was also limited due to the access to the literature concerning analyzed problem within European countries. Last, but not least limitation is scope of discussion. The author does not have many years of experience, thus the scope and depth of discussions might be not sufficient at some point.

\section{The Problem}

The relationship between lack of proper education and training and poverty or social exclusion was confirmed in many academic works in the last decade. Examples of such works are Mihai M., Titan E., Madea D. (2015), King K., McGrath S., Rose P., (2007) or Hayyat A., Chughtai H. S.(2015). Mihai M. et al. described poverty as a "vicious circle" from which it is difficult to escape (2015). Thus, a child born in poverty is not or is just little prepared for education. It means that such children are disfavored from the very beginning of their life. This, in turn, may lead to inability to integrate and learning difficulties. Sociologists and researchers speak together with a single voice; children born in poverty or in socially excluded families have a lower chance of succeeding in education, and thus escape from this vicious circle of poverty. However, poverty and social exclusion have many roots, including economic growth, income inequalities, infant and maternal deaths, violence at home and in society, education and training, or vulnerability to HIV and AIDS. Among them, one factor stands out significantly: education and training. Obviously, not every person without adequate education or training lives in poverty, but most of those who live suffer from lack of education and training. Horace Mann, an American public-school precursor, called education the "great equalizer of the conditions of men"(1848). Thus, it can be said that people who suffer from lack of proper education or access to additional training might end up in the gap of unemployment, earnings, or even life expectancy. The research objective is to determine the correlation between the participation rate in education and training and the rate of people at risk of poverty and social exclusion.

\section{The Data}

The participation rate in education in training vary a lot between European countries. The smallest value among the countries the countries analyzed was observed in 2018 and was equal to $0,9 \%$. On the other hand, the highest value was observed in 2019 and was equal to $34,3 \%$. The range of values varies from $27,6 \%$ points in 2020 to $33 \%$ points in 2019 . This indicates a strong variability of the data, which was confirmed by other statistical measurements, including the standard deviation and relative mean and standard deviation. The results are presented in Table 3. 
Table 3. Measures of variability applied to participation rate in the education and training variable

Measures of Variability

\begin{tabular}{llllllllll}
\hline & min & max & $\begin{array}{l}\text { ran } \\
\text { ge }\end{array}$ & $\begin{array}{l}\text { Standard } \\
\text { deviation } \\
\text { : }\end{array}$ & $\begin{array}{l}\text { Vari } \\
\text { ance }\end{array}$ & $\begin{array}{l}\text { Mean } \\
\text { deviation: }\end{array}$ & $\begin{array}{l}\text { Relative } \\
\text { mean } \\
\text { deviation }\end{array}$ & $\begin{array}{l}\text { Relative } \\
\text { standard } \\
\text { dev. }\end{array}$ & $\begin{array}{l}\text { Quartile } \\
\text { deviation }\end{array}$ \\
\hline $\mathbf{2 0 1 6}$ & 1,2 & 31,4 & 30,2 & 8,54 & 75,14 & 6,49 & $91,05 \%$ & 1,20 & 5,625 \\
$\mathbf{2 0 1 7}$ & 1,1 & 31,2 & 30,1 & 8,54 & 75,17 & 6,78 & $95,47 \%$ & 1,20 & 6,1875 \\
$\mathbf{2 0 1 8}$ & 0,9 & 31,6 & 30,7 & 8,43 & 73,18 & 6,62 & $94,88 \%$ & 1,21 & 6,3375 \\
$\mathbf{2 0 1 9}$ & 1,3 & 34,3 & 33 & 8,92 & 81,96 & 6,86 & $93,37 \%$ & 1,21 & 7,1125 \\
$\mathbf{2 0 2 0}$ & 1 & 28,6 & 27,6 & 7,64 & 60,14 & 5,53 & $89,14 \%$ & 1,23 & 5,6125 \\
\hline
\end{tabular}

Source: Own elaboration based on data from Eurostat.

The standard deviation, which measures how much, on average, each measurement differs from the arithmetic mean of the data, had a slight decreasing tendency between 2016 and 2018, which means that the participation rate in education and training values became slightly more similar. Then the standard deviation increased by almost 0.5 percent points and decreased by almost 1.2 percent points. The same conclusion was obtained after analysis of variance, a statistical measurement that gauges how far the numbers in the set are from the mean and how far they are from each other. It can be seen that the highest variance was in 2019 .

The second variable included in this study is the rate of people being at risk of poverty or social exclusion in chosen European countries. The smallest value among analyzed countries was observed in 2020 and was equal to $10,5 \%$. On the other hand, the highest value was observed in 2016 and was equal to $41,3 \%$. The range of values varies from $41,3 \%$ points in 2016 to $33,8 \%$ points in 2020 . This indicates a strong variability of the data, which was confirmed by other statistical measurements, including the standard deviation and relative mean and standard deviation. Hopefully, the highest value, the lowest value, and range, are becoming lower and lower, which indicates that rate of people being at risk of poverty and social exclusion is becoming lower and lower. The outcomes are presented in Table 4. 
Table 4. Measures of variability applied to people at risk of poverty and social exclusion variable 2022, Vol. 12, No. 1

\begin{tabular}{lllllllllll}
\hline \multicolumn{1}{l}{ Measures of Variability } & & & & & \\
\hline & min & max & $\begin{array}{l}\text { rang } \\
\text { e }\end{array}$ & $\begin{array}{l}\text { Standard } \\
\text { deviation }\end{array}$ & Variance & $\begin{array}{l}\text { Mean } \\
\text { deviation }\end{array}$ & $\begin{array}{l}\text { Relative } \\
\text { mean } \\
\text { deviation }\end{array}$ & $\begin{array}{l}\text { Relative Quartile } \\
\text { standar } \\
\text { d dev. }\end{array}$ & $\begin{array}{l}\text { deviatio } \\
\text { n }\end{array}$ \\
\hline $\mathbf{2 0 1 6}$ & 12,2 & 53,5 & 41,3 & 9,35 & 90,01 & 7,13 & 0,28 & 0,37 & 5,75 \\
$\mathbf{2 0 1 7}$ & 12,2 & 51,8 & 39,6 & 9,01 & 83,66 & 7,11 & 0,29 & 0,37 & 5,70 \\
$\mathbf{2 0 1 8}$ & 11 & 49 & 38 & 8,16 & 68,86 & 6,98 & 0,30 & 0,35 & 5,33 \\
$\mathbf{2 0 1 9}$ & 10,6 & 46,2 & 35,6 & 7,63 & 59,93 & 7,35 & 0,35 & 0,36 & 4,55 \\
$\mathbf{2 0 2 0}$ & 10,5 & 44,3 & 33,8 & 7,29 & 54,77 & 6,21 & 0,30 & 0,35 & 4,25 \\
\hline
\end{tabular}

Source: Own elaboration based on data from Eurostat.

The standard deviation, a measure of the disparity of each value from the sample mean, has a decreasing tendency, which indicates a decrease in the variability of the data. The same was confirmed by calculating the mean deviation, the relative mean deviation, and the relative standard deviation. As the lowest and the highest values are decreasing, the following conclusion might be formulated: Regardless of the initial value of the participation rate in education and training in studied countries, adults from those countries are becoming less and less interested in participation in education and training.

\section{Lower and Upper Confidence Limits}

As mentioned above, some countries had to be excluded from the research due to the lack of values for some years within the analyzed period. Thus, the lower and upper confidence limits were calculated. As the standard deviation of the population is unknown, to calculate it, an Excel formula '= CONFIDENCE.T' was used. The results are shown in Table5

Table 5. Lower and upper confidence limit for participation rate in education and training with significance level $=99 \%$

\section{Participation rate in education and training.}

$$
\text { Significance level }=99 \%
$$

\begin{tabular}{llllll}
\cline { 2 - 5 } & $\mathbf{2 0 1 6}$ & $\mathbf{2 0 1 7}$ & $\mathbf{2 0 1 8}$ & $\mathbf{2 0 1 9}$ & $\mathbf{2 0 2 0}$ \\
\hline LCL & 8,0 & 7,6 & 7,7 & 8,1 & 6,9 \\
UPL & 14,5 & 15,5 & 15,7 & 15,8 & 13,8 \\
\hline
\end{tabular}

Source: Own elaboration based on data from Eurostat. 


\section{Macrothink}

International Journal of Learning and Development

ISSN 2164-4063 2022, Vol. 12, No. 1

In 2016 , the population mean of participation rate in education and training is between $8 \%$ and $14,5 \%$, while in 2020 it is between $6,9 \%$ and $13,8 \%$, with $99 \%$ of confidence. It means that an average rate of participation in education and training is decreasing, indicating lower interest of adults in participation in education and training.

The same was done for the level of people in poverty or social exclusion. Calculations was done using the same Excel function. The results are presented in Table 6.

Table 6. Lower and upper confidence limit for people at risk of poverty or social exclusion with significance level $=99 \%$

\begin{tabular}{llllll}
\hline \multicolumn{7}{l}{ People at risk of poverty or social exclusion } \\
\cline { 2 - 5 } & \multicolumn{2}{l}{ Sigificance level $\mathbf{9} \mathbf{9 9 \%}$} & & \\
\cline { 2 - 5 } & 2016 & 2017 & 2018 & 2019 & 2020 \\
\hline LCL & 15,4 & 14,6 & 13,8 & 13,3 & 13,2 \\
UPL & 35,0 & 34,0 & 32,6 & 31,6 & 30,9 \\
\hline
\end{tabular}

Source: Own elaboration based on data from Eurostat.

According to Table 6, the population mean of people at risk of poverty or social exclusion is gradually decreasing. In 2016, the population mean is between $15,4 \%$ and $35 \%$, while in 2020 it is between $13,2 \%$ and $30,9 \%$. It indicates that the population mean of people at risk of poverty and social exclusion is constantly decreasing, as the lower confidence limit decreased by more than 2 percent points and the upper confidence limit by 41 percent points.

\section{The Correlation}

To check whether there is any linear correlation between chosen variables, the Pearson product-moment correlation of the coefficient was calculated. According to the following formula:

$$
\mathrm{r}_{x y}=\frac{\operatorname{Cov}(x, y)}{\sigma_{x} \sigma_{y}}
$$

Where, 
$\mathrm{r}_{x y}=$ Pearson product - moment correlation coefficient

$\operatorname{Cov}(x, y)=$ Covariance of variables $x$ and $y$

$\sigma_{x}=$ Standard deviation of variable $x$

$\sigma_{y}=$ Standard deviation of variable $y$

The procedure was performed for each year separately. The results are presented in Table 7.

Table 7. Pearson's correlation coefficient between participation rate in education and training and people at risk of poverty and social exclusion, between 2016 to 2020, for European countries included in research

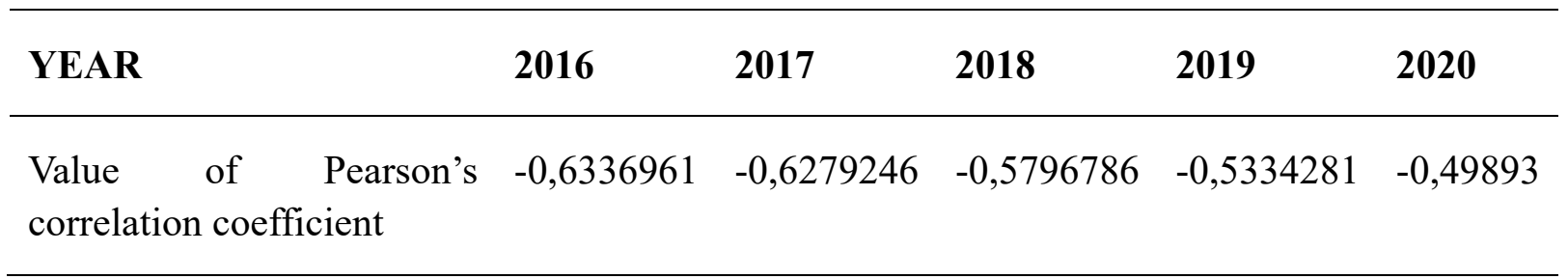

Source: Own elaboration based on data from Eurostat.

As correlation is an effect size, the strength of the correlation can be verbally described. For this purpose, the guidance suggested by Evans (1996), for the absolute value of rxy, can be used. The guidance is presented in Table 8 .

Table 8. Verbal description of the strength of Pearson correlation coefficient based on its numerical value

Relationship

$0,00-0,19$

Very weak

$0,20-0,39$

Weak

$0,40-0,59$

Moderate

$0,60-0,79$

Strong

$0,80-1,00$

Very Strong

Source: Own elaboration, based on Evans, R., H., "An Analysis of Criterion Variable Reliability in Conjoint Analysis". 
In case of all analyzed periods negative correlation occurred. It is caused by the consistent move of one variable in opposite direction to one second variable. In 2016, the linear correlation between the participation rate in education and training and people at risk of poverty and social exclusion is equal to almost 0,634 . Using the guide suggested by Evans, such a value of Pearson coefficient of correlation, indicates strong negative linear relationship between studied variables. In 2020, the linear correlation between mentioned above variables is estimated to be equal to almost 0,499, which, according to Evans, suggests strong negative linear correlation. The negative correlation means that for every positive change in people at risk of poverty or social exclusion, participation trade in education and training experiences a decrease of 0.9. In general, based on the values of Pearson's correlation coefficient, a decreasing trend can be observed, which makes the variables less linearly correlated.

As the linear correlation was indicated by Pearson's correlation of the coefficient, the coefficient of determination was calculated. The coefficient of determination is equal to the squares of Pearson's coefficient of correlation. The results are presented in Table 9.

Table 9. Values of Coefficient of Determination for Studied Sample

\begin{tabular}{llllll}
\hline YEAR & $\mathbf{2 0 1 6}$ & $\mathbf{2 0 1 7}$ & $\mathbf{2 0 1 8}$ & $\mathbf{2 0 1 9}$ & $\mathbf{2 0 2 0}$ \\
\hline $\begin{array}{l}\text { Value of the } \\
\text { coefficient of } \\
\text { determination }\end{array}$ & 0,401571 & 0,394289 & 0,336027 & 0,284546 & 0,248931 \\
\hline
\end{tabular}

Source: Developing your own elaboration based on data from Eurostat.

In 2016, $0.41(41 \%)$ of the variation in the people at risk of poverty and social exclusion in the sample can be explained by the participation rate in education and training. However, in 2020 , only 0,25 (25\%), of the variation in the people at risk of poverty and social exclusion in the sample can be explained by the participation rate in education and training. It means that in 2016 participation in education and training was an important factor, which influenced the level of people in poverty and social exclusion. It has changed over the analyzed period, the coefficient of determination increased by more than 15 percent points. According to this, it can be said that another factor causing decrease in poverty should be found.

\section{The Hipothesis Testing}

As it was discussed above, Pearson coefficient of correlation, rxy, determines the strength and direction of linear correlation between two variables. Although, the reliability of the linear model is also affected by number of values observed in the studied sample. Thus, to assess the significance of the correlation of coefficient, hypothesis testing was performed. Based on it the decision if the strength of the linear correlation in the studied sample is enough to use this model for the population was made. The analysis was performed for each analyzed year. 


\section{IMacrothink}

International Journal of Learning and Development

ISSN 2164-4063 2022, Vol. 12, No. 1

First, the objective and hypothesis of the research were stated. They are presented in Table 10.

Table 10. The objective of the research and the hypothesizes for hypothesis testing

Research objective: The coefficient of correlation is equal to 0.

\begin{tabular}{lllll}
\hline $\mathbf{2 0 1 6}$ & $\mathbf{2 0 1 7}$ & $\mathbf{2 0 1 8}$ & $\mathbf{2 0 1 9}$ & $\mathbf{2 0 2 0}$ \\
\hline $\mathrm{H} 0: \mathrm{p}=0$ & $\mathrm{H} 0: \mathrm{p}=0$ & $\mathrm{H} 0: \mathrm{p}=0$ & $\mathrm{H} 0: \mathrm{p}=0$ & $\mathrm{H} 0: \mathrm{p}=0$ \\
$\mathrm{H} 1: \mathrm{p}=/=0$ & $\mathrm{H} 1: \mathrm{p}=/=0$ & $\mathrm{H} 1: \mathrm{p}=/=0$ & $\mathrm{H} 1: \mathrm{p}=/=0$ & $\mathrm{H} 1: \mathrm{p}=/=0$ \\
\hline
\end{tabular}

Source: Own elaboration based on own sources.

Where, $\mathrm{p}$ stands for Pearson's correlation coefficient of the population. This hypothesis testing aims to decide if the value of the population correlation coefficient equal to $p$ is close to zero and significantly different from zero. Thus, null hypothesizes from Table 10 mean in words as follow: "The Pearson coefficient of correlation of the population is not significantly different from zero.". On the other hand, alternative hypotheses mean that 'The Pearson coefficient of correlation of the population is significantly different from zero.". There are two different methods to make this decision: a p-value two-tailed test and the rejection region test. The methods should provide the same test results. For both, calculation of test statistics, is required. For this purpose, the formula suggested by Gerald Keller in "Statistics for Management and Economics"(2018) was used.

$$
t=r \sqrt{\frac{n-2}{1-r^{2}}}
$$

where

$\mathrm{t}=$ test statistics for testing

$\mathrm{r}=$ sample Pearson coefficient of correlation

$\mathrm{n}=$ number of observations in the studied sample

$\mathrm{n}-2=$ degree of freedom, provided that the variables are normally distributed in bivariate.

The following values of the test statistics were calculated. 
Tabela 11. The values of test statistics

\begin{tabular}{|c|c|c|c|c|c|c|c|c|}
\hline 2016 & \multicolumn{2}{|c|}{2017} & \multicolumn{2}{|c|}{2018} & \multicolumn{2}{|c|}{2019} & \multicolumn{2}{|c|}{2020} \\
\hline $\mathrm{t} \quad-4,6339$ & $\mathrm{t}$ & $-4,5640$ & $\mathrm{t}$ & $-4,0243$ & $\mathrm{t}$ & $-3,5675$ & $\mathrm{t}$ & $-3,2567$ \\
\hline
\end{tabular}

Source: Own elaboration based on own sources.

First, the rejection region method was performed. For this purpose, the confidence level equal to $99 \%$ (alpha $=0,01$ ) was adjusted for each period analyzed. Therefore, for each year, the rejection region is as follow $(-\infty ;-2,575) \mathrm{u}(2,575 ;+\infty)$. Based on this, the following decision was made: The value of test statistics does fall into the rejection region, which means that the null hypothesis should be rejected for every analyzed period. Thus, there is sufficient evidence to infer that the population correlation coefficient is not equal to 0 .

The same procedure was repeated using a different method, the p-value two-tailed test. The calculations made for each year analyzed are presented in Table 12.

Table 12. Two-tailed P-value test

\begin{tabular}{lll}
\hline Year & Probability & Value \\
\hline $\mathbf{2 0 1 6}$ & $P(Z<-4,6339)+1-\mathrm{P}(\mathrm{Z}<4,6339)$ & Close to 0 \\
$\mathbf{2 0 1 7}$ & $P(Z<-4,5640)+1-\mathrm{P}(\mathrm{Z}<4,5640)$ & Close to 0 \\
$\mathbf{2 0 1 8}$ & $P(Z<-4,0243)+1-\mathrm{P}(\mathrm{Z}<4,0243)$ & Close to 0 \\
$\mathbf{2 0 1 9}$ & $P(Z<-3,5675)+1-\mathrm{P}(\mathrm{Z}<3,5675)$ & Close to 0 \\
$\mathbf{2 0 2 0}$ & $P(Z<-3,2567)+1-\mathrm{P}(\mathrm{Z}<3,2567)$ & Close to 0 \\
\hline
\end{tabular}

Source: Own elaboration based on own sources.

For each year, the probability was very close to 0 , which means that there is overwhelming evidence that the alternative hypothesis is true. Repeated hypothesis test confirmed the test performed using the rejection region.

\section{Conclusions}

Although, in 2016 and 2017, a strong linear correlation was detected between the participation rate in education and training and people at risk of poverty or social exclusion, 
its significance gradually decreased. In 2020, the Pearson coefficient of correlation indicated moderate linear correlation. The determination coefficient indicated that in $2016,41 \%$ and in $202025 \%$ of the variation in people at risk of poverty and social exclusion in the sample could be explained by the participation rate in education and training. The coefficient of determination decreased by more than 15 percent points. According to this, it can be said that another factor causing decrease in poverty should be found. The population is becoming more and more well educated and interested in postgraduate training, which in turn causes higher probability of success in the future. It should be emphasized that children born in poverty or in socially excluded families have a lower chance of succeeding in education and thus escape from the vicious circle of poverty. Thus, education should still be perceived as an important factor and the main tool to fight against poverty.

\section{References}

Anikin, A. V. (2021). Training poverty in India: Reassessing the effect of social ascription. International Journal of Training and Development, 25(3), 277-300. https://doi.org/10.1111/ijtd.12231

Evans, R. H. (1996). An Analysis of Criterion Variable Reliability in Conjoint Analysis. Perceptual and Motor Skills, 84, 988-990. https://doi.org/10.2466/pms.1996.82.3.988

Hayyat, A., \& Chughtai, H. S. (2015). The Impact of Vocational Training on Poverty Alleviation Through Moderation Role of Foreign Funds; Evidence from Southern Punjab. Management Studies and Economic Systems, 2(2), 157-171. https://doi.org/10.12816/0019400

Keller, G (2018). Statistical for Management and Education. Cengage Learning

Khan, A. M., \& Aness, J. A. (2014). The role of training in reducing poverty: The case of the ultra-poor in Bangladesh. International Journal of Training and Development, 18(4). https://doi.org/10.1111/ijtd.12041

King. K., \& Palmer. R. (2007). Skills development and poverty reduction: a state-of-the-art review. Retrieved from https://www.etf.europa.eu/sites/default/files/m/C12578310056925B C12573AF00520109_NOTE79TKHJ.pdf

Mihai, M., Titan, E., \& Manea, D. (2015). Education and Poverty. Procedia Economics and Finance, 32, 855-860. https://doi.org/10.1016/S2212-5671(15)01532-4

Shonchoy, A., Raihan, S., \& Fujii, T. (2017). Reducing Extreme Poverty Through Skill Training for Industry Job Placement. GLMLIC Policy Brief No. 9. Retrieved from https://g2lm-lic.iza.org/publications/pb/pb9/

Wallenborn, M. (2009). The impact of vocational education on poverty reduction, quality assurance and mobility on regional labor markets - selected EU-funded schemes. European Journal of Vocational Training, 47, 2009/2. Retrieved from https://files.eric.ed.gov/fulltext/EJ887044.pdf 
Appendices

Appendix 1. Graph of 'Participation rate in education and training between 2016 and 2020 in European countries' Sources: Own elaboration based on Eurostat

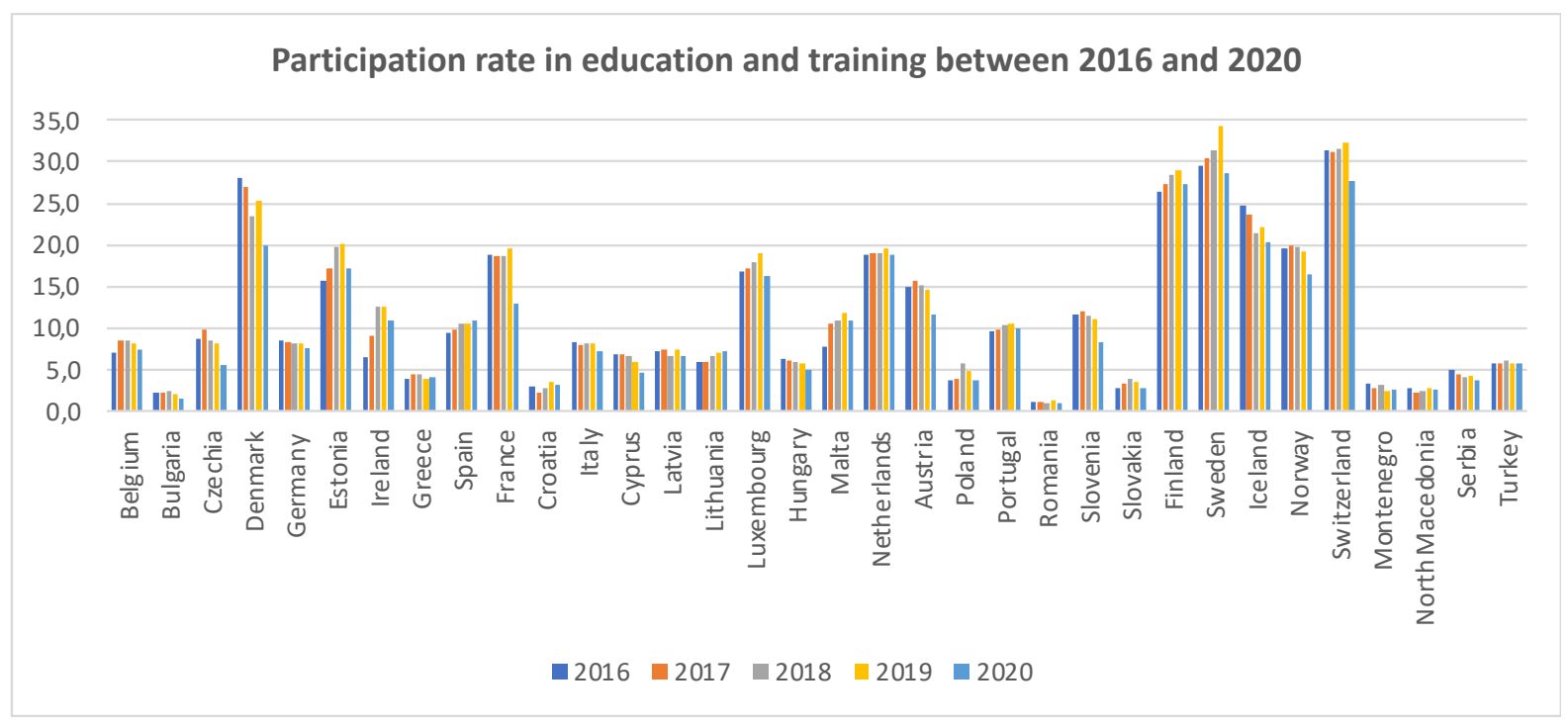

Appendix 2. Graph of 'People at risk of poverty or social exclusion between 2016 and 2020 in European countries' Sources: Own elaboration based on Eurostat

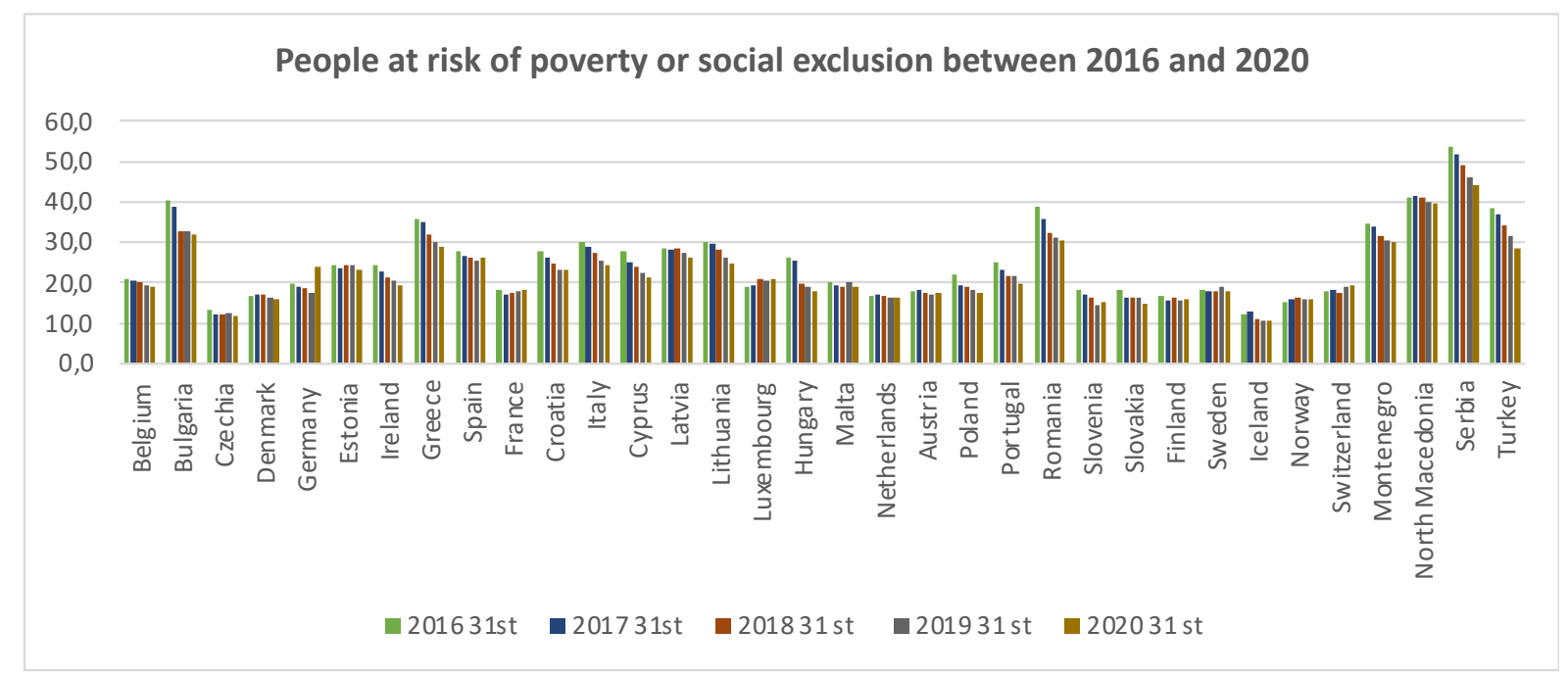

\section{Copyright Disclaimer}

Copyright for this article is retained by the author(s), with first publication rights granted to the journal.

This is an open-access article distributed under the terms and conditions of the Creative Commons Attribution license (http://creativecommons.org/licenses/by/4.0/). 